\title{
Cellular Immunity Before and After Leptin Replacement Therapy
}

\author{
Gilberto Jorge Paz-Filho ${ }^{1}$, Tuncay Delibasi ${ }^{2}$, Halil Kutlu Erol ${ }^{2}$, Ma-Li Wong ${ }^{1}$ and Julio Licinio ${ }^{1}$ \\ ${ }^{1}$ John Curtin School of Medical Research, Australian National University, Canberra, Australia \\ and ${ }^{2}$ Center of Pharmacogenomics of the Department of Psychiatry and Behavioral Sciences, \\ University of Miami Miller School of Medicine, Miami, FL, USA
}

\section{ABSTRACT}

Background: The few identified leptin-deficient children have immune deficiency.

Aims: To evaluate whether a newly-identified leptin-deficient boy has immune defects; to assess the immune changes during leptin replacement.

Methods: A 5 year-old boy with congenital leptin deficiency was evaluated before, 2 weeks and 6 weeks after the initiation of recombinant methionyl human leptin. Thymic volume was measured by computed tomography. Humoral immunity was assessed by measuring levels of several immunoglobulins. Cellular immunity was evaluated by the analysis of lymphocyte proliferation in response to mitogens. Lymphocyte subsets were quantified by flow cytometry.

Results: At baseline, thymic volume was increased. The lymphocyte subsets count and humoral/cellular immunities were normal. After treatment, proliferative response to mitogens increased by 1.5- to 3-fold, and lymphocyte count decreased by $17 \%$.

Conclusions: Immune defects are not an obligatory feature of congenital leptin deficiency. Even in the absence of significant immune defects, leptin replacement therapy enhanced T-cell responsiveness.

\section{KEY WORDS}

deficiency, immunity, leptin, obesity, T cell

\footnotetext{
Reprint address:

Julio Licinio

The John Curtin School of Medical Research

Building 131

Garran Road

Acton, ACT 0200, Australia

e-mail: julio.licinio@anu.edu.au
}

\section{INTRODUCTION}

Leptin is one of several cytokine-like hormones produced by adipocytes, also known as adipokines, whose multiple functions go beyond that of regulating food intake. We have previously described the endocrine, metabolic, anthropometric, and neurological effects of leptin ${ }^{1-12}$, by assessing its effects on the only adults to date identified as leptindeficient. More recently, we have reported the effects of leptin replacement on the neurocognitive development of a leptin-deficient boy, from the same family as the adult patients ${ }^{13}$. We have observed that leptin replacement led to (i) substantial weight loss, (ii) resolution of hypertension and hyperinsulinemia, (iii) improvements of lipid profile, and (iv) enhancement of neurocognitive development of that child ${ }^{13}$. However, the effects of leptin replacement on immunity in that patient have not yet been characterized.

As an adipokine, the hallmark of leptin biology is pleiotropy, characterized by multiple and marked effects on metabolic and immune functions ${ }^{14-16}$. Its immune effects include the stimulation of hematopoiesis and lymphopoiesis, the activation of monocytes, dendritic cells (DC) and macrophages (leading to the production of Th1 type cytokines) ${ }^{17}$, the maturation and survival of $\mathrm{DC}^{18}$, the activation of neutrophils and natural killer (NK) cells (and the subsequent stimulation of their gene expression, of the production of reactive oxygen species and of chemotaxis) ${ }^{19-22}$, and the modulation of the adaptive immunity (by enhancing $\mathrm{T}$ cell survival and stimulating the production of pro-inflammatory cytokines such as IFN- $\gamma$ and IL-2) ${ }^{23}$. Leptin also regulates thymic homeostasis and prevents apoptosis.

ClinicalTrials.gov Identifier: NCT00659828

http://clinicaltrials.gov/ct2/show/NCT00659828 
In humans, leptin deficiency is associated with substantially increased mortality, due to increased risk of infection at early ages ${ }^{8}$. Leptin-deficient children have a marked reduction in the CD4+ Tcell count and reduced T-cell proliferation ${ }^{24}$. Patients with leptin receptor mutations have a modest reduction in the absolute $\mathrm{CD} 4+\mathrm{T}$-cell counts, but with similar CD4+:CD8+ ratios. Also, those patients have a compensatory increase in CD19+ cells, and reduced proliferative responses to polyclonal stimuli specific to $\mathrm{T}$ cells ${ }^{25}$. Cytokine expression impairment is more pronounced in leptin-deficient patients, as compared to patients with leptin receptor mutations. Treatment of a child with congenital leptin deficiency with r-metHuLeptin led to a substantial increase in white blood cell count, and to the marked improvement of asthmatic crisis ${ }^{26}$. Conversely, in humans without congenital leptin deficiency, it is speculated that hypoleptinemia associated with malnutrition and nutritional deficiency might protect individuals from autoimmune diseases, but predispose to infections ${ }^{27}$.

Therefore, immune dysfunction is thought to be common in patients with disorders of leptin function. Mortality is increased in both situations: leptin deficiency and mutations of the leptin receptor. The aim of this study was to describe immune findings in a leptin-deficient boy, before and during the course of treatment with recombinant methionyl human leptin (r-metHuLeptin).

\section{PATIENT AND METHODS}

The patient is a 5 year- 1 month-old boy born to a highly consanguineous Turkish family. Three of his relatives are homozygous for the nonconservative missense leptin gene mutation (Cys-to-Thr in codon 105). The mutation renders them leptin deficient, and the endocrine and metabolic findings have been described elsewhere ${ }^{3,13}$. Apart from being obese, the child had no medical problems, and no important history of infectious diseases was noted.

Replacement treatment with r-metHuLeptin (initially supplied by Amgen, Inc. Thousand Oaks, CA, USA and subsequently by Amylin, San Diego, CA, USA) was started at age 5 years 1 month. The drug was administered once a day in the evening $(18.00-20.00 \mathrm{~h})$, with a starting dose of 1.36 $\mathrm{mg}$ /day SQ. Details regarding treatment procedures and outcomes are described elsewhere ${ }^{13}$.

This n-of-1 trial was approved by the University of California, Los Angeles Institutional Review Board (UCLA IRB), and informed parental consent and patient's assent was obtained for all studies. The patient was evaluated at the UCLA General Clinical Research Center (GCRC) as an in-patient.

Thymus computed tomography was performed before treatment, by obtaining axial scans of the chest with a slice thickness of $3 \mathrm{~mm}$ from the thoracic inlet to the lower chest without the administration of an oral contrast. Thymic volume was calculated after $3 \mathrm{D}$ reconstruction using the Vitrea software, and compared to the normal children's reference range.

Humoral immunity was assessed at baseline and six weeks after r-metHuLeptin was initiated, by measuring the levels of IgG (including subclasses), IgA, IgM and IgE. Titers of antibodies against Haemophilus influenza B, Tetanus toxoid, and pneumococcal antibody IgG were also evaluated before and after treatment.

Flow cytometry was undertaken before and six weeks after treatment initiation. The percent and absolute count of the lymphocyte subsets (CD3, CD4, CD8, CD19 and CD16/CD56) were calculated by using four-color flow cytometry analysis, based on the selection of CD45+ non-granular cells.

Analysis of lymphocyte proliferation in response to mitogens was performed before, two weeks and six weeks after treatment initiation. Lymphocyte proliferation in response to the mitogens phytohemaglutinin (PHA), concanavalin A (Con-A) and pokeweed mitogen (PWM) was determined 4 days after their administration. The response to Tetanus and Candida antigens was assessed on day 7. Briefly, the patient's purified peripheral blood mononuclear cells (lymphocytes and monocytes) were incubated with the test substances and, during the last 24 hours of the culture, tritiated thymidine was added to the medium. The extent of proliferation was determined by measuring the radioactivity taken up by the dividing cells and was reported 
as a stimulation index (SI). This is the ratio of radioactivity (as counts per minute $[\mathrm{CPM}]$ ) with stimulation to the CPM, or without stimulation (background).

\section{RESULTS}

Before treatment, thymic soft tissue was well visualized in the retrosternal location, without evidence of fatty infiltration. The thymic volume was type 4 (defined as moderate amount, of greater extent, as compared to the volumes seen in normal children $)^{28}$.

At baseline, humoral immunity was normal, as levels of IgG (including subclasses), IgA, and IgM were within the normal range. Levels of $\operatorname{IgE}$ were above normal (368 IU/ml, normal $<20 \mathrm{IU} / \mathrm{ml})$, indicating the likelihood of atopic allergy. There were no changes in the levels of immunoglobulins six weeks after leptin replacement was initiated. Titers of Haemophilus influenza B antibodies were undetectable, and titers of Tetanus toxoid antibody were $>7.0 \mathrm{IU} / \mathrm{ml}$, indicating previous vaccination against Tetanus, but not against Haemophilus influenza B. Titers of pneumococcal antibody IgG were below $2 \mu \mathrm{g} / \mathrm{ml}$ for types $1,4,6 \mathrm{~B}, 9 \mathrm{~N}, 12 \mathrm{~F}, 14$, $23 \mathrm{~F}$ and $18 \mathrm{C}$, and above $2 \mu \mathrm{g} / \mathrm{ml}$ for types $3,8,19 \mathrm{~F}$ and 7F. Vaccination with Pneumovax 23 (Merck \& Co, Inc, Rahway, NJ, USA) was administered, and pneumococcal antibody IgG titers were reassessed after 6 weeks (under leptin replacement). These titers increased at least 2-fold (except for antibodies type 19F, 23F, 7F and 18C).

Before treatment, all cell populations were within normal ranges (by complete blood count with differential and blood smear), including lymphocytes $\left(3.5 \times 10^{3} / \mu 1\right)$. Six weeks after leptin replacement was initiated, the absolute lymphocyte count was still normal $\left(2.9 \times 10^{3} / \mu \mathrm{l}\right)$ but lower than baseline. When analyzed by flow cytometry, the absolute (cells $/ \mathrm{cmm}$ ) and the percent counts of lymphocyte subsets were all normal at baseline. Concomitantly with the decrease in the absolute lymphocyte count, the absolute counts of CD3, CD4 and CD19 cells decreased six weeks after leptin was initiated (Table 1).

Cell-mediated immunity was assessed by lymphocyte proliferate response to mitogens PHA, Con-
A, PWM, Tetanus and Candida. There was a strong proliferative response to mitogens and to Candida, and no proliferative response to Tetanus, before and 6 weeks after leptin was initiated (Table 2).

\section{DISCUSSION}

In this study, we showed that, in our patient, congenital leptin deficiency is associated with normal humoral and cellular immunities, except for a very low proliferative response to Tetanus. In the short-term, r-metHuLeptin did not increase the proliferative response to Tetanus, whereas responses to other mitogens increased by up to 3-fold. Concomitantly, leptin replacement decreased the absolute lymphocyte count (though still within normal range). Finally, thymic volume was increased at baseline, as compared to the children's reference volume.

Previous studies report that leptin-deficient children have higher susceptibility to infections due to $\mathrm{T}$ cell hyporesponsiveness ${ }^{24,26}$. In discordance with those findings, our patient did not have a history of recurrent infections, cell lymphopenia or impairment of lymphocyte function. On the contrary, after r-metHuLeptin was initiated, his absolute lymphocyte counts decreased. However, his proliferative responses to mitogens (other than Tetanus toxoid) did increase in response to leptin.

The absence of recurrent infections is strong evidence that our patient, besides having a different genotype (missense, instead of frameshift mutation), also has a different phenotype in regard to immunity, which did not change significantly after r-metHuLeptin was initiated. This may be the reason as to why he survived leptin deficiency. However, other obese children in his family, who were presumably leptin deficient, died early in life due to febrile illnesses (presumably infections). It is unclear why our patient has a different immune phenotype from the other leptindeficient children identified so far. Possibly, the different types of mutations leading to leptin deficiency can determine diverse phenotypes. In addition, we hypothesize that the absence of infections in our patient, as opposed to the occurrence of fatal infections among relatives in the same family, might be explained by the 'variable expressivity' phenomenon. Although more frequently seen in auto- 
TABLE 1

Lymphocyte subsets before and 6 weeks after initiation of leptin, measured by flow cytometry

\begin{tabular}{lccc}
\hline & Before leptin & $\begin{array}{c}\text { After 6 weeks } \\
\text { on leptin }\end{array}$ & $\begin{array}{c}\text { Children's reference } \\
\text { range }\end{array}$ \\
\hline CD3 & $63 \%(2261)$ & $64 \%(1580)$ & $62-80 \%(1610-4230)$ \\
CD4 & $34 \%(1144)$ & $33 \%(766)$ & $35-51 \%(900-2860)$ \\
CD8 & $27 \%(916)$ & $27 \%(627)$ & $22-38 \%(630-1910)$ \\
CD4/CD8 ratio & 1.25 & 1.22 & $1.0-2.1$ \\
CD19 & $27 \%(1006)$ & $22 \%(574)$ & $21-28 \%(700-1300)$ \\
CD16+CD56 & $9 \%(341)$ & $11 \%(273)$ & \\
\hline
\end{tabular}

Values expressed as percentages (cells/cmm).

TABLE 2

Proliferative response (SI) to phytohemagglutinin (PHA), concanavalin A (Con-A), pokeweed mitogen (PWM), Tetanus and Candida, before and after initiation of leptin

\begin{tabular}{lccc}
\hline & Baseline & 2 weeks & 6 weeks \\
\hline PHA $5 \mu \mathbf{g}$ & $184(177)$ & $290(83)$ & $373(117)$ \\
PHA $1 \mu \mathbf{g}$ & $25(21)$ & $36(7)$ & $44(19)$ \\
Con-A $5 \mu \mathbf{g}$ & $40(32)$ & $109(34)$ & $86(47)$ \\
Con-A $1 \mu \mathbf{g}$ & $17(17)$ & $33(13)$ & $40(19)$ \\
PWM $5 \mu \mathbf{g}$ & $28(25)$ & $49(21)$ & $43(28)$ \\
PWM $1 \mu \mathbf{g}$ & $34(28)$ & $71(22)$ & $46(30)$ \\
Tetanus $2 \mu \mathbf{g}$ & $2(7)$ & $27(63)$ & $5(49)$ \\
Tetanus $1 \mu \mathbf{g}$ & $1(6)$ & $19(54)$ & $2(33)$ \\
Candida $10 \mu \mathbf{g}$ & $45(5)$ & $211(27)$ & $99(28)$ \\
Candida $5 \mu \mathbf{g}$ & $32(2)$ & $184(20)$ & $75(32)$ \\
\hline
\end{tabular}

$\mathrm{SI}=$ stimulation index.

Controls' SIs are shown in parentheses.

somal dominant diseases, variable expressivity can occur in autosomal recessive traits, leading to different degrees of expression of the disease ${ }^{29}$.

This study has some limitations. First, although we compared data with age-matched reference values, we did not include normal controls. Second, due to the rarity of the disease, only one leptin- deficient child was included in the study. Finally, we did not repeat the studies due to restrictions regarding the volume of blood that was allowed to be drawn.

In conclusion, our data demonstrate that immune defects are not a constant feature of genetically-based leptin deficiency. The immune 
phenotype associated with leptin deficiency appears to be determined not only by the absence of leptin, but also by the genotype and by variable expressivity. We also show here that even in the absence of significant immune defects, leptin replacement therapy enhances $\mathrm{T}$ cell responsiveness. Further studies need to evaluate the outcomes of leptin replacement therapy in hypo- or aleptinemic patients with normal immune responses (such as patients with lipodystrophy or anorexia nervosa). The potential role of leptin treatment for disorders of immunity may be either beneficial (by increasing immune response against infections) or negative (by facilitating autoimmune diseases), depending on the clinical context.

\section{ACKNOWLEDGEMENTS}

The authors are grateful to the members of the UCLA GCRC for their contributions to the clinical care of the leptin-deficient patient. This study was supported by National Institutes of Health grants R01DK058851, K24RR016966 (to J.L.), R01DK 063240, K24RR017365 (to M.-L.W.) and M01RR 000865 (to G. Levey), and by a grant from Amgen, Inc. During the course of this study, Amgen, Inc. and Amylin Pharmaceuticals, Inc. provided rMetHuLeptin. Neither Amgen, Inc. nor Amylin Pharmaceuticals, Inc. contributed to the design, analysis, or writing of this study.

Conflict of interest: none.

\section{REFERENCES}

1. Andreev VP, Paz-Filho G, Wong ML, Licinio J. Deconvolution of insulin secretion, insulin hepatic extraction post-hepatic delivery rates and sensitivity during 24-hour standardized meals: time course of glucose homeostasis in leptin replacement treatment. Horm Metab Res 2009; 41: 142-151.

2. Baicy K, London ED, Monterosso J, Wong ML, Delibasi T, Sharma A, Licinio J. Leptin replacement alters brain response to food cues in genetically leptindeficient adults. Proc Natl Acad Sci USA 2007; 104: 18276-18279.

3. Licinio J, Caglayan S, Ozata M, Yildiz BO, de Miranda PB, O'Kirwan F, Whitby R, Liang L, Cohen P, Bhasin S, Krauss RM, Veldhuis JD, Wagner AJ, DePaoli AM, McCann SM, Wong ML. Phenotypic effects of leptin replacement on morbid obesity, diabetes mellitus, hypogonadism, and behavior in leptin-deficient adults. Proc Natl Acad Sci USA 2004; 101: 4531-4536.

4. Licinio J, Milane M, Thakur S, Whelan F, Yildiz BO, Delibasi T, de Miranda PB, Ozata M, Bolu E, Depaoli A, Wong ML. Effects of leptin on intake of specific micro- and macronutrients in a woman with leptin gene deficiency studied off and on leptin at stable body weight. Appetite 2007; 49: 594-599.

5. Licinio J, Ribeiro L, Busnello JV, Delibasi T, Thakur S, Elashoff RM, Sharma A, Jardack PM, Depaoli AM, Wong ML. Effects of leptin replacement on macro- and micronutrient preferences. Int J Obes (Lond) 2007; 31: 1859-1863.

6. Mantzoros CS, Ozata M, Negrao AB, Ziotopoulou M, Caglayan S, Suchard M, Cogswell RJ, Negro P, Elashoff RM, Liberty V, Wong M-L, Veldhuis JD, Ozdemir IC, Gold PW, Flier JS, Licinio J. Synchronicity of frequently sampled TSH and leptin concentrations in healthy adults and leptin deficient subjects: evidence for possible partial TSH regulation by leptin in humans. J Clin Endocrinol Metab 2001; 86: 3284-3291.

7. Matochik JA, London ED, Yildiz BO, Ozata M, Caglayan S, DePaoli AM, Wong ML, Licinio J. Effect of leptin replacement on brain structure in genetically leptin-deficient adults. J Clin Endocrinol Metab 2005; 90: 2851-2854.

8. Ozata M, Ozdemir IC, Licinio J. Human leptin deficiency caused by a missense mutation: multiple endocrine defects, decreased sympathetic tone, and immune system dysfunction indicate new targets for leptin action, greater central than peripheral resistance to the effects of leptin, and spontaneous correction of leptin-mediated defects. J Clin Endocrinol Metab 1999; 84: 3686-3695.

9. Paz-Filho G, Esposito K, Hurwitz B, Sharma A, Dong C, Andreev V, Delibasi T, Erol H, Ayala A, Wong ML, Licinio J. Changes in insulin sensitivity during leptin replacement therapy in leptin-deficient patients. Am J Physiol Endocrinol Metab 2008; 295: E1401-1408.

10. Paz-Filho GJ, Andrews D, Esposito K, Erol HK, Delibasi T, Wong ML, Licinio J. Effects of leptin replacement on risk factors for cardiovascular disease in genetically leptin-deficient subjects. Horm Metab Res 2009; 41: 164-167.

11. Paz-Filho GJ, Ayala A, Esposito K, Erol HK, Delibasi T, Hurwitz BE, Wong ML, Licinio J. Effects of leptin on lipid metabolism. Horm Metab Res 2008; 40: 572574.

12. Williamson DA, Ravussin E, Wong ML, Wagner A, Dipaoli A, Caglayan S, Ozata M, Martin C, Walden H, Arnett C, Licinio J. Microanalysis of eating behavior of three leptin deficient adults treated with leptin therapy. Appetite 2005; 45: 75-80.

13. Paz-Filho GJ, Babikian T, Asarnow R, Esposito K, Erol HK, Wong ML, Licinio J. Leptin replacement 
improves cognitive development. PLoS One 2008; 3: e3098.

14. Howard JK, Lord GM, Matarese G, Vendetti S, Ghatei MA, Ritter MA, Lechler RI, Bloom SR. Leptin protects mice from starvation-induced lymphoid atrophy and increases thymic cellularity in ob/ob mice. J Clin Invest 1999; 104: 1051-1059.

15. Lam QL, Lu L. Role of leptin in immunity. Cell Mol Immunol 2007; 4: 1-13.

16. Lord GM, Matarese G, Howard JK, Baker RJ, Bloom SR, Lechler RI. Leptin modulates the T-cell immune response and reverses starvation-induced immunosuppression. Nature 1998; 394: 897-901.

17. Mattioli B, Straface E, Quaranta MG, Giordani L, Viora M. Leptin promotes differentiation and survival of human dendritic cells and licenses them for Th1 priming. J Immunol 2005; 174: 6820-6828.

18. Lam QL, Liu S, Cao X, Lu L. Involvement of leptin signaling in the survival and maturation of bone marrow-derived dendritic cells. Eur J Immunol 2006; 36: 3118-3130.

19. Caldefie-Chezet F, Poulin A, Vasson MP. Leptin regulates functional capacities of polymorphonuclear neutrophils. Free Radic Res 2003; 37: 809-814.

20. Zhao Y, Sun R, You L, Gao C, Tian Z. Expression of leptin receptors and response to leptin stimulation of human natural killer cell lines. Biochem Biophys Res Commun 2003; 300: 247-252.

21. Tian Z, Sun R, Wei H, Gao B. Impaired natural killer (NK) cell activity in leptin receptor deficient mice: leptin as a critical regulator in NK cell development and activation. Biochem Biophys Res Commun 2002; 298: 297-302.

22. Santos-Alvarez J, Goberna R, Sanchez-Margalet V. Human leptin stimulates proliferation and activation of human circulating monocytes. Cell Immunol 1999; 194: 6-11.

23. Loffreda S, Yang SQ, Lin HZ, Karp CL, Brengman
ML, Wang DJ, Klein AS, Bulkley GB, Bao C, Noble PW, Lane MD, Diehl AM. Leptin regulates proinflammatory immune responses. FASEB J 1998; 12: 57-65.

24. Farooqi IS, Matarese G, Lord GM, Keogh JM, Lawrence E, Agwu C, Sanna V, Jebb SA, Perna F, Fontana S, Lechler RI, DePaoli AM, O'Rahilly S. Beneficial effects of leptin on obesity, $\mathrm{T}$ cell hyporesponsiveness, and neuroendocrine/metabolic dysfunction of human congenital leptin deficiency. J Clin Invest 2002; 110: 1093-1103.

25. Farooqi IS, Wangensteen T, Collins S, Kimber W, Matarese G, Keogh JM, Lank E, Bottomley B, LopezFernandez J, Ferraz-Amaro I, Dattani MT, Ercan O, Myhre AG, Retterstol L, Stanhope R, Edge JA, McKenzie S, Lessan N, Ghodsi M, De Rosa V, Perna F, Fontana S, Barroso I, Undlien DE, O'Rahilly S. Clinical and molecular genetic spectrum of congenital deficiency of the leptin receptor. N Engl J Med 2007; 356: 237-247.

26. Gibson WT, Farooqi IS, Moreau M, DePaoli AM, Lawrence E, O'Rahilly S, Trussell RA. Congenital leptin deficiency due to homozygosity for the Delta133G mutation: report of another case and evaluation of response to four years of leptin therapy. J Clin Endocrinol Metab 2004; 89: 4821-4826.

27. Matarese G, Leiter EH, La Cava A. Leptin in autoimmunity: many questions, some answers. Tissue Antigens 2007; 70: 87-95.

28. McCune JM, Loftus R, Schmidt DK, Carroll P, Webster D, Swor-Yim LB, Francis IR, Gross BH, Grant RM. High prevalence of thymic tissue in adults with human immunodeficiency virus-1 infection. J Clin Invest 1998; 101: 2301-2308.

29. Gottlieb B, Beitel LK, Trifiro MA. Somatic mosaicism and variable expressivity. Trends Genet 2001; 17: 7982. 